\title{
Sudden Cardiac Death
}

National Cancer Institute

\section{Source}

National Cancer Institute. Sudden Cardiac Death. NCI Thesaurus. Code C50911.

An unexpected natural death from a cardiac cause within a short time period from the onset of symptoms. 